\title{
Spor Lisesi Öğrencilerinin Beslenme Alışkanlıklarının İncelenmesi (Sinop İli Örneği)
}

\author{
Ahmet MOR $^{1} \quad$ Gökhan IPEKOĞLU ${ }^{1} \quad$ Cansel ARSLANOĞLU ${ }^{1}$ \\ ${ }^{1}$ Sinop Üniversitesi, Spor Bilimleri Fakültesi, SINOP
}

Künye: Mor, A., İpekoğlu, G. ve Arslanoğlu, C. (2018). Spor Lisesi Öğrencilerinin Beslenme Alışkanlıklarının İncelenmesi (Sinop İli Örneği). Gaziantep Üniversitesi Spor Bilimleri Dergisi, 3(3): 67-77.

\section{Öz}

Bu çalışmanın amacı; Spor lisesi öğrencilerinin beslenme alışkanlıklarının incelenmesidir. Çalışmaya, Sinop Şehit Bülent Yalçın Spor Lisesi öğrencilerinden (erkek $n=65$, kadın $n=33$ ) olmak üzere toplam 98 öğrenci katılmıştır. Çalışmada, araştırmacı tarafından geliştirilen beslenme ve öğünlere ilişkin görüşleri, spor ve beslenmeye yönelik tutumları ve destek ürünü kullanma tutumlarını incelemeye yönelik, 15 maddeden oluşan anket uygulanmıştır. Anketin güvenirliliğini ölçmek için Cronbach Alfa katsayısından yararlanılmıştır. Yapılan güvenirlilik analizi sonucu, Cronbach Alfa katsayısı 0.79 olarak bulunmuştur. Çalışmada elde edilen bulgular frekans dağılımı ve yüzdeler ile özetlenerek yorumlanmıştır. Araştırmada; spor lisesi öğrencilerinin spor ve beslenme arasındaki ilişkiyi \%87.8 bir oranla vurgulamalarına rağmen, beslenme ve öğünlere ilişkin görüşlerinin ve beslenmeye yönelik bilgi düzeylerinin yetersiz olduğu görülmektedir. Ayrıca öğrencilerin \%62.2'si okul müfredatında beslenme ile ilgili yeterince bilgi olmadığı görüşündedir. Sonuç olarak spor liselerinde müfredatın gözden geçirilmesinin yanı sıra, sağlıklı ve düzenli beslenmeye yönelik eğitici konferanslar ve bilimsel etkinlikler yapılmalı ve öğrencilerde sağlıklı yaşam ve sporda beslenmeye yönelik bir kültür oluşturulmalıdır.

\section{Orijinal Makale}

Yayın Bilgileri

Gönderi Tarihi: 26.07.2018

Kabul Tarihi:31.08.2018

Yayın Tarihi: 24.09.2018

Sorumlu Yazar

e-mail: canseloglu@sinop.edu.tr

DOI: 10.31680/gaunjss.447961

Anahtar kelimeler: Beslenme, besin takviyesi, spor lisesi.

\section{An Investigation of Nutritional Habits of Sport High School Students (Sample of Sinop Province)}

\begin{abstract}
The aim of this study was to examine the level of the nutritional habits of the sport high school students. The research consisted of 98 students (male $n=65$. female $=33$ ) from Sinop Şehit Bülent Sport High School. A questionnaire that developed by researchers were applied to evaluate the nutritional habits of students. The Cronbach Alpha coefficient was used to measure the reliability of the questionnaire. As a result of the reliability analysis, the Cronbach Alpha coefficient was found to be 0.79 . It is seen that the knowledge and attitudes towards nutrition and meals are inadequate. Although the sports high school students emphasize the relationship between sport and nutrition at a rate of $87.8 \%$. Besides, $62.2 \%$ of the students think that there is not enough information about nutrition in the school curriculum. As a result, in addition to the revision of curriculum in sport high schools, educational conferences and scientific activities must be organized related to healthy living and sport nutrition.
\end{abstract}

\section{Original Article}

Article Info

Received: 26.07 .2018

Accepted: 31.08.2018

Published: 24.09.2018

\section{Corresponding Author}

e-mail: canseloglu@sinop.edu.tr

Keywords: Nutrition, dietary supplement, sport high school. 


\section{Giriş}

Son yıllarda sporcu beslenmesi, egzersiz ve antrenman bilimleri birbirlerini bilgileriyle destekleyen ortak bir çalışma alanı haline gelmiştir (Mor ve ark., 2018). Beslenme, sporcuların antrenman programlarında önemli bir ögedir. Egzersiz ve sporcu antrenmanlarının bazı atletlerde beslenme ihtiyaçlarını artırdığı düşünülmesine rağmen, dengeli diyetle birlikte uygun kaloriler besin gereksinimini büyük ölçüde karşılayabilir. Buna rağmen, çeşitli nedenlerden dolayı bütün sporcuların artan besin intiyaçlarını doğal diyetlerle karşılaması mümkün değildir ve bu yüzden eksiklikleri gidermek amacıyla doğal suplementlere de başvurulur (McDowall, 2007).

İyi bir beslenme programı antrenmanın kalitesini ve performansı artırdığı, toparlanma sürecini de hızlandırdığı için sporcular için önemlidir (Mor ve ark., 2018). Bir sporcunun ne yediğinin ve içtiğinin, egzersiz performansı ile birlikte; sağlık, vücut ağırlığı ve kompozisyonu, egzersiz sırasındaki fizyolojik değişimler ve egzersiz sonrası toparlanma gibi nedenlerden dolayı önemli olduğundan şüphe yoktur. Bu sebeplerden dolayı, egzersiz performansını yükseltmek isteyen sporcular, iyi bir beslenme ve hidrasyon stratejileri izlemeli, besin takviyelerini ve ergojenik yardımcıları da bilinçli kullanmalı, kilo alıp verme uygulamalarına dikkat etmeli ve yeterli miktarda çeşitli yiyecekler tüketmelidir (Manore ve ark., 2000).

Beslenme, özellikle kas dokularında hücresel yenilenme, yeni proteinlerin oluşumu, enerjinin yenilenmesi, optimal sıvı ve elektrolit seviyelerinin yerine getirilmesi ve doku onarımı için önemlidir. Bununla birlikte beslenme, egzersiz talepleri ve sporcuların intiyaçları doğrultusunda dikkatlice planlandığında, atletlerin egzersiz sonrası toparlanmasına da katkıda bulunur. Genel olarak metabolik, kardiyovasküler, solunumsal ve hormonal değişimlerin hızlı bir şekilde egzersiz öncesi değerlere dönmesi açısından önemlidir. Başka bir deyişle; beslenme toparlanma evresinde metabolizmanın katabolik evreden anabolik evreye geçişinde önemli bir rol oynar (Ziegenfuss ve ark., 2015). Sporda beslenme metabolizmadan metabolizmaya farklılık gösterdiği gibi yapılan spor dallarına göre de farklılıklar gösterir. Birey için; üst düzeyde bir performans ve devamlılık gösterebilmek, sakatlanmaları engelleyebilmek, sakatlandığında ise daha çabuk iyileşebilmek için doğru ve tam anlamıyla sağlıklı beslenebilme şarttır (Aracı, 2006).

Sporcunun beslenme ihtiyaçlarının öncelikli gelen belirleyicisi antrenman programıdır. Bu program sporcunun enerji harcamasını ve yaşam şeklini etkileyen 
önemli bir faktördür. Elit sporcularda antrenman her gün gerçekleştirilen bir faaliyettir. Bu nedenle toplam günlük enerji harcamasının önemli bir kısmını oluşturmaktadır. Böylesi bir program sporcunun sadece enerji ve besin öğesi gereksinimlerini etkilemekle kalmayıp aynı zamanda beslenme alışkanlıklarını ve sosyal yaşam tarzına ilişkin diğer aktivitelerini de etkilemektedir. Dengeli ve düzenli beslenme antrenmanın önemli bir bileşenidir ve tıpkı fiziksel kondisyon da olduğu gibi yarışmadan bir-iki gün önce uygulanan değil, devamlıık ve alışkanlık gerektiren bir süreç olmalıdır. Eğer sporcu antrenman veya yarışma sezonu süresince optimal beslenme rejimi uygulamamışsa performans optimal düzeyde gerçekleştirilemez (Başoğlu, 2004). Yeterli ve dengeli beslenme sporcuların sportif başarısını garanti etmemekle birlikte, yetersiz ve dengesiz beslenmenin ortaya çıkaracağı olumsuz etkileri engellediği için bu popülasyonda önemli bir etken olmaktadır (Ersoy, 2008).

Son zamanlarda, sporcu beslenmesi antrenmanın bir parçası olmuştur ve popülerliği de artmıştır. Her yaş, yetenek ve beceri düzeyindeki sporcular için uyarlanan beslenme programı, sporcuların performansını artırır ve toparlanma sürecini hızlandııır (Poole ve ark., 2010). Egzersiz yapanlar performanslarını artırmak için enerji ve besin öğelerini yeterli almalı, dengeli ve çeşitli beslenmelidirler (Akyol ve ark., 2008).

Araştırmanın amacı spor lisesinde öğrenim gören öğrencilerin beslenme alışkanlıkları ve besin destek ürün kullanımı hakkındaki eğilimlerinin belirlenmesidir.

\section{Yöntem}

Çalışmaya, Sinop Şehit Bülent Yalçın Spor Lisesi öğrencilerinden (erkek $n=65$, kadın $n=33$ ) olmak üzere toplam 98 öğrenci katılmıştır. Çalışma için Sinop Üniversitesi İnsan Araştırmaları Etik Kurulundan (26.02.2018 tarih 2018/14 karar) ve diğer kurumlardan gerekli izinler alınmış ve öğrenciler gönüllülük esasına göre katılmıştır. Anketler, 2017-2018 Eğitim-öğretim yılı bahar döneminde uygulanmış, uygulama öncesi öğrencilere konuya ilişkin ön bilgi verilmiş ve anket sorularına içtenlikle cevap vermeleri istenmiştir.

Veri toplama aracı olarak iki bölümden oluşan bir anket formu kullanılııştır. Hazırık aşamasında, literatür taramalarından elde edilen bilgiler yardımıyla, kavramsal yapı ve ana çerçeve belirlenmiştir. Araştırmada kullanılan anket formu kişisel olarak hazırlanan sorular ve benzer konuda yapılmış araştırmalardan yararlanılarak hazırlanmışıı. Birinci bölümü kişisel bilgi formu, ikinci bölümü 
öğrencilerin beslenme ve öğünlere ilişkin görüşleri, spor ve beslenmeye yönelik tutumları ve destek ürünü kullanma bilgilerini içeren 15 soruluk anket formu oluşturmuştur. Anketin güvenirliğini ölçmek için Cronbach Alfa katsayısından yararlanılmış ve yapılan analizi sonucu, Cronbach Alfa güvenirlik katsayısı 0.79 olarak bulunmuştur. Bu sonuç, anket sonuçlarının güvenilir olduğunu göstermektedir. Çalışmanın istatiksel analizinde SPSS 22 paket programı kullanılmıştır. Çalışmada elde edilen bulgular frekans dağılımı ve yüzdeler ile özetlenerek yorumlanmıştır.

\section{Bulgular}

Tablo 1. Öğrencilerin sosyo-demografik özellikleri

\begin{tabular}{|c|c|c|c|}
\hline Değişkenler & & $n$ & $\%$ \\
\hline \multirow{2}{*}{ Cinsiyet } & Erkek & 65 & 66.3 \\
\hline & Kadın & 33 & 33.7 \\
\hline \multirow{4}{*}{ Yaş } & 15 yaş & 36 & 36.7 \\
\hline & 16 yaş & 32 & 32.7 \\
\hline & 17 yaş & 11 & 11.2 \\
\hline & 18 yaş & 19 & 19.4 \\
\hline \multirow{4}{*}{ Spor yaşı } & $1-3 \mathrm{yll}$ & 7 & 7.1 \\
\hline & $4-6 \mathrm{yll}$ & 46 & 46.9 \\
\hline & $7-9 \mathrm{yll}$ & 26 & 26.6 \\
\hline & 10 ve üstü yıl & 19 & 19.4 \\
\hline \multirow{4}{*}{ Sinıf } & 1. SinIf & 41 & 41.8 \\
\hline & 2. Sinif & 21 & 21.4 \\
\hline & 3. SinIf & 15 & 15.4 \\
\hline & 4. Sinıf & 21 & 21.4 \\
\hline \multirow{2}{*}{$\begin{array}{l}\text { Herhangi bir kulüpte } \\
\text { oynama durumu }\end{array}$} & Evet & 73 & 74.5 \\
\hline & Hayır & 25 & 25.5 \\
\hline
\end{tabular}

Tablo 2. Öğrencilerin beslenme ve öğünlere ilişsin görüşleri

\begin{tabular}{|c|c|c|c|}
\hline & & $\mathbf{n}$ & $\%$ \\
\hline \multirow{2}{*}{$\begin{array}{c}\text { Günde kaç öğün yemek } \\
\text { yersiniz? }\end{array}$} & 3 öğün 3 ara & 7 & 7.1 \\
\hline & Dikkat etmem & 91 & 92.9 \\
\hline \multirow{2}{*}{$\begin{array}{l}\text { Ana öğünlerde makro ve } \\
\text { mikro ürünler tüketiyor } \\
\text { musunuz? }\end{array}$} & Evet & 77 & 78.6 \\
\hline & Hayır & 21 & 21.4 \\
\hline \multirow{2}{*}{ Öğün atlar mısınız? } & Evet & 64 & 65.3 \\
\hline & Hayır & 34 & 34.7 \\
\hline \multirow{6}{*}{ Öğün atlama nedenleriniz? } & Zaman yetersizliği & 10 & 15.6 \\
\hline & İştahsızlık & 16 & 25.0 \\
\hline & Geç kalma & 12 & 18.8 \\
\hline & Zayıflama isteği & 3 & 4.7 \\
\hline & Alışkanlığının olmaması & 6 & 9.4 \\
\hline & Ekonomik nedenler & 17 & 26.5 \\
\hline \multirow{5}{*}{$\begin{array}{l}\text { Günlük almanız gereken } \\
\text { kaloriyi neye göre } \\
\text { hesaplıyorsunuz? }\end{array}$} & Antrenör & 28 & 28.6 \\
\hline & Kulüp doktoru & 2 & 2.0 \\
\hline & Yazılı ve görsel medya & 7 & 7.1 \\
\hline & Kitap ve benzeri & 9 & 9.2 \\
\hline & Arkadaş ve çevre & 52 & 53.1 \\
\hline
\end{tabular}


Tablo 3. Öğrencilerin spor ve beslenmeye yönelik tutumları

\begin{tabular}{|c|c|c|c|}
\hline & & $\mathbf{n}$ & $\%$ \\
\hline \multirow{3}{*}{$\begin{array}{c}\text { Beslenme alışkanlıkları ile } \\
\text { sporda başarı arasında ilişki } \\
\text { var mıdır? }\end{array}$} & Evet & 2 & 2.0 \\
\hline & Hayır & 86 & 87.8 \\
\hline & Fikrim yok & 10 & 10.2 \\
\hline \multirow{4}{*}{$\begin{array}{l}\text { Antrenmandan veya } \\
\text { müsabakadan ne kadar } \\
\text { önce yemek yersiniz? }\end{array}$} & 30 dakika & 6 & 6.1 \\
\hline & 1-2 saat & 61 & 62.2 \\
\hline & 3-4 saat & 26 & 26.5 \\
\hline & Dikkat etmem & 5 & 5.1 \\
\hline \multirow{4}{*}{$\begin{array}{l}\text { Antrenmandan veya } \\
\text { müsabakadan ne kadar } \\
\text { sonra yemek yersiniz? }\end{array}$} & İlk 30 dakika & 18 & 18.4 \\
\hline & 1 saat & 49 & 50.0 \\
\hline & 2-3 saat & 17 & 17.3 \\
\hline & Dikkat etmem & 14 & 14.3 \\
\hline \multirow{2}{*}{$\begin{array}{l}\text { Antrenman veya müsabaka } \\
\text { öncesi ve sonrası sonra sıvı } \\
\text { alımına dikkat eder misiniz? }\end{array}$} & Evet & 80 & 81.6 \\
\hline & Hayır & 18 & 18.4 \\
\hline \multirow{3}{*}{$\begin{array}{l}\text { Antrenman esnasında sıvı } \\
\text { tüketir misiniz? }\end{array}$} & Evet & 73 & 74.5 \\
\hline & Hayır & 19 & 19.4 \\
\hline & Dikkat etmem & 6 & 6.1 \\
\hline \multirow{2}{*}{$\begin{array}{c}\text { Beslenme ile ilgili okul } \\
\text { müfredatında yeterince bilgi } \\
\text { var mı? }\end{array}$} & Evet & 37 & 37.8 \\
\hline & Hayır & 61 & 62.2 \\
\hline
\end{tabular}

Tablo 4. Öğrencilerin destek ürünü kullanma durumu

\begin{tabular}{|c|c|c|c|}
\hline & & $\mathbf{n}$ & $\%$ \\
\hline \multirow{2}{*}{$\begin{array}{c}\text { Düzenli bir şekilde } \\
\text { destekleyici ürün kullanıyor } \\
\text { musunuz? }\end{array}$} & Evet & 24 & 24.5 \\
\hline & Hayır & 74 & 75.5 \\
\hline \multirow{3}{*}{$\begin{array}{c}\text { Eğer destek ürün } \\
\text { kullanıyorsanız hangi } \\
\text { amaçla kullanıyorsunuz? }\end{array}$} & Kas geliştirme & 7 & 29.2 \\
\hline & Performans arttırma & 15 & 62.5 \\
\hline & Diğer & 2 & 8.3 \\
\hline \multirow{4}{*}{$\begin{array}{l}\text { Ne kadar zamandır bu ürünü } \\
\text { kullanıyorsunuz? }\end{array}$} & $0-6$ ay & 11 & 45.8 \\
\hline & 7 ay -1 yıl & 7 & 29.2 \\
\hline & $2-3$ yıl & 4 & 16.7 \\
\hline & 3 yıl ve üzeri & 2 & 8.3 \\
\hline \multirow{3}{*}{$\begin{array}{l}\text { Beslenme destek ürünü kim } \\
\text { tarafından önerildi? }\end{array}$} & Antrenörüm & 11 & 45.8 \\
\hline & Öğretmenim & 2 & 8.3 \\
\hline & Kendim & 11 & 45.8 \\
\hline
\end{tabular}

\section{Tartışma ve Sonuç}

$\mathrm{Bu}$ araştırmada spor lisesinde öğrenim gören öğrencilerin beslenme alışkanlıkları ve besin destek ürün kullanımı hakkındaki eğilimleri belirlenmiştir.

Öğrencilerin beslenme ve öğünlerine ilişkin görüşleri incelendiğinde; öğrencilerin \%92.9'unun öğün sayısına dikkat etmediği, \%78.6'sının ana öğünlerde makro ve mikro besinleri tükettiği, \%65.3'ünün öğün atladığı, öğün atlama nedenleri arasında en fazla iştahsızlık (\%25.0) olduğu ve \%53.1'i günlük almaları gereken kaloriyi arkadaş ve çevreden etkilenerek hesapladıkları görülmektedir (Tablo 2). 
Beslenme ve yeme tutumları ile ilgili literatürde çok sayıda araştırma bulunmaktadır. Tanrıverdi ve ark. (2011) lise öğrencilerini yeme davranışları açısından değerlendirmiştir. Öğrencilerin \%69.5'inin öğün atladığını ve öğünler içinde en çok sabah kahvaltısını atladığını, öğün atlama nedeni olarak yeme isteğinin olmamasını belirtmişlerdir. Ayrıca katılımcıların \%66.8'i yeterli ve dengeli beslenme konusunda öğretmen ve radyo-televizyondan bilgi aldıklarını belirtmişlerdir. Sevindi ve ark. (2007) yaptığı çalışmada, erkek katııımcıların \%71'i, kadınların \%77'sinin öğün atladığı tespit edilmiştir. Güleç ve ark. (2008), Türk ve ark. (2007), Aksoydan ve Çakır (2011) yaptığı çalışmalarda, katıııcıların yüksek oranda öğün atladıkları, en fazla atlanılan öğünün sabah kahvaltısı olduğu ve atlama sebebi olarak yeme isteğinin olmaması olarak belirtilmektedir. Ülkemizde en fazla atlanan öğün sabah kahvaltısı olmasına rağmen, farklı ülkelerdeki adölesanlar üzerinde yapılan çalışmalarda kahvaltı etme oranı Portekiz'de \%87, İspanya'da \%88, İtalya'da \%78 olarak literatürde yer almıştır (De Jong ve ark., 2009). Lise öğrencileri üzerinde yapılan başka bir çalışmada (Uzdil ve ark., 2017), öğrencilerin yeme tutumlarının antropometrik ölçümler ve sosyo-demografik özelliklerden etkilenmediği belirlenmiştir. Ancak öğrencilerin yaş ve cinsiyetlerine özgü tüketmeleri önerilen besinlerin çoğunu karşılayamadıkları belirtilmiştir. Bu çalışmalardan da anlaşılabileceği gibi özellikle adölesan dönemde gözlenen öğün atlama, oldukça sık rastlanılan bir davranış olarak karşımıza çıkmaktadır. Öğün atlamaya bağlı olarak yeterli ve dengeli beslenememek, öğrencilerde büyüme ve gelişme sorunları ortaya çıkarabileceği gibi okul başarısına da olumsuz yansıyabilecektir. Oysaki dengeli ve yeterli beslenmede öğün atlanmaması ve 3 öğünün de düzenli aralıklarla tüketilmesi, gelecek kuşaklara iyi bir beslenme alışkanlığı kazandırıması açısından oldukça önem taşımaktadır.

Öğrencilerin spor ve beslenmeye yönelik tutumları incelendiğinde; beslenme alışkanlıkları ile sporda başarı arasında ilişki olduğuna inanmayan \%87.8 gibi büyük bir grup karşımıza çıkmaktadır. Antrenman ya da müsabakadan 1-2 saat önce yemek yediklerini söyleyenlerin oranı \% $62.2 \mathrm{iken}$, antrenman veya müsabakadan 1 saat sonra yemek yediklerini söyleyenlerin oranı \%51'dir. Katılımcıların \%81.6'sı antrenmandan önce ve sonra sıvı aldıklarını, \%74.5'i de antrenman esnasında sıVı tükettiklerini belirtmişlerdir. Spor Lisesi öğrencilerine göre, okul müfredatında beslenme ile ilgili yeterince bilgi olmadığını söyleyenler \%62.2 gibi çoğunluğu kapsamaktadır (Tablo 3). Yaşam boyu sürecek sağlık davranışlarının ağırlıkı olarak adölesan dönemde kazanıldığı düşünüldüğünde, bu dönemde edinilecek sağlıksız 
beslenme davranışlarının sağlık açısından olası riskleri de beraberinde getirmesi kaçınılmazdır. 357 lise birinci sınıf öğrencisi üzerinde yapılan çalışmada, katılımcılara 21 soruluk beslenme ve fiziksel aktivite anketi uygulanmıştır. Öğrencilerin \%49.7'sinin düzenli spor aktivitesine katıldığı, kızların daha sağlıklı beslenme davranışına sahip olduğu ancak tüm öğrencilerin besin piramidi konusunda yeterli bilgi düzeyine sahip olmadıkları ve sağlıklı beslenmedikleri belirtilmiştir (Akman ve ark., 2012). 12-19 yaş arasındaki adölesanlarda beslenme alışkanlıkları ve kardiovasküler risk faktörlerinin incelendiği çalışmada kızlarda inaktivite düzeyinin erkeklere göre daha yüksek olduğu (sırası ile \%37.6 ve \%29.6), beslenme açısından özellikle meyve ve sebze alımlarının düşük olduğu belirtilmiştir (Baş ve ark., 2005). Adölesanların diyet kaliteleri üzerine yapılan başka bir çalışmada, araştırmacılar okul kantinlerinde satılan atıştırmalıkların zararına dikkat çekmiş ve okul kantinlerinde mutlaka bazı düzenlemeler yapılması gerektiğini söylemişlerdir (Keshani ve ark., 2018). Bulduk ve ark. (2018) lise öğrencilerinin beslenme tutumları üzerine yaptığı araştırmada ise, öğrencilerin düzensiz yeme tutumları sebebiyle vücutlarından daha az memnun olmalarına dikkat çekmiş, beslenme tutumlarının desteklenmesi ve vücut ağırlığı ile birlikte beden imajının iyileştirilmesi için beslenme eğitiminin gerekli olduğunu tespit etmişlerdir. Abood ve ark. (2004) yaptığı başka bir çalışmada, Florida'da bir kadın futbol takımı ile bir kadın yüzme takımından seçilen sporcuların beslenme bilgi düzeylerinin yetersiz ve sadece antrenmana yönelik olduğu ortaya çıkmıştır. Üniversite öğrencileri üzerinde yapılan başka bir çalışmada, deneklerin \%70.1'inin daha önce spor yaptığı, \%27.6'sının yapmadığı saptanmıştır. Ayrıca daha önce spor yapma fırsatını elde etmiş olmasına rağmen bunu aynı oranda spor yapma alışkanlığını yaşamları içerisine katamadıkları belirtilmiştir. Aynı çalışmada öğrencilerin düzenli besleme alışkanlığına sahip olmadığı da belirtilmektedir (Korkmaz, 2010).

Douglas (1984) tarafından yapılan bir çalışmada, lisedeki öğrencilerin beslenme bilgi düzeylerinin başarı ile bir ilişkisi olup olmadığına bakılmış ve kadın sporcularda beslenme ile başarı arasında ilişki olduğu belirtilmiştir. Literatürde müsabaka öncesi son öğünün en az 3 saat önceden alınmış olması öngörülmektedir. Bu doğrultuda, çalışmamızdaki 1-2 saat cevabı (\%62.2), öğrencilerin bu konuda yeterli bilgi sahibi olmadıklarını göstermektedir.

Çalışmamızda spor lisesi öğrencilerinin besin destek ürünü kullanma durumları incelendiğinde; \%24.5’lik bir öğrenci grubunun besin desteği kullandığı görülmektedir. 
Besin desteği kullananların \%62.5'i performansını artırma amaçlı olarak kullandığını belirtmiştir. 0-6 ay aralığında besin desteği kullananların oranı 45.8 iken, en az 3 yıldır destek ürün kullananların oranı 8.3'tür. Besin destek ürününü antrenörünün yardımıyla ya da kendisi tarafından kullanıldığını söyleyenlerin oranı \%45.8 olarak eşit düzeydedir (Tablo 4).

Sporcuların besin desteği kullanma nedenleri, performansı veya toparlanmayı desteklemek, sağlı̆ın devamlıı̆̆ıı sağlamak, beslenme durumunu geliştirmek şeklinde sıralanabilir. Olması gerekenin aksine, besin desteği kullanan sporcular diyetisyen veya diğer spor ile ilgili sağlık personelleri yerine, arkadaş, takım arkadaşları, koç, aile ve internet aracılığıyla edindikleri bilgilere dayanarak besin desteklerini kullanmaktadırlar (Braun, 2009). Sobal ve Marquart (2004) tarafından yapılan araştırmaya göre adölesan sporcuların \%62'si bu tür ürünlerin performansı artırdığına inanmaktadır. Çalışmamızda da besin desteği kullananların \%62.7'si performansı artırma amaçlı olarak, antrenöründen ya da kendi inisiyatifiyle (\%45.8) besin desteğini kullandığını belirtmiştir. Goston ve Correia (2010) ise çalışmamızdan farklı olarak, spor salonlarına giden gençlerin daha çok kas kütlesini artırmak için besin destek ürünlerini kullandığını belirtmektedir.

Son yıllarda besin destek kullanımına ilişkin çalışmaların sayısı artmıştır. Helvacı ve Açkurt'un (2018) yaptığı araştırmada besin destek ürünleri hakkında bilgi alma konusunda en güvenilen kaynağın antrenörler (\%38.3) olduğu belirtilmiştir. İnternet gibi güvenilir olmayan bilgi kaynaklarından yararlananların oranı ise belirtilen çalışmada \%24'tür. Farklı çalışmalarda da antrenörlere, doktor ve diyetisyenlerden daha fazla güvenildiği belirtilmektedir (Whitehouse ve Lawlis, 2017: Abbey ve ark., 2017). Besin destek ürünü kullanımı ile ilgili yurtiçinde yapılan araştırmada; bireylerin birden fazla besin destek ürünü kullandıkları ve ürünü kullanım amaçları sorulduğunda, erkeklerde ilk üç sırayı zindelik, performansı artırmak ve bağışıklığı artırmak kadınlarda ise, bağışıklığı artırmak, zindelik ve yaşlanmayı geciktirmek almıştır (Ünsal ve ark., 2010).

Araştırma sonucunda, spor lisesi öğrencilerinin beslenme bilgi alışkanlıklarının ve besin destek kullanımına ilişkin bilgi düzeylerinin yeterli olmadığı görülmektedir. Bu sonuç gösteriyor ki, öğrencilerin beslenme ile ilgili bilgilerinin artırımasına önem verilmelidir. Çünkü sportif performansın yüksek olması için beslenme, en az antrenman kadar önemlidir. Bu bilgilerin öğrencilerle paylaşıması ile kazandırılacak doğru/düzenli beslenme tutumları ve sağlıkı beslenme alışkanlıkları, genel sağık ile 
birlikte sportif performansı da yükseltecektir. Ayrıca, spor lisesi öğrencilerinin önemli bir bölümünün ailelerinden uzakta eğitim görmeleri ve sürekli fiziksel aktiviteyle iç içe olmaları nedeniyle de, özel beslenme önerilerinde bulunulması gerekmektedir.

\section{Kaynaklar}

Abbey EL, Wright CJ, Kirkpatrick CM, 2017. Nutrition Practices And Knowledge Among NCAA Division III Football Players. Journal of the International Society of Sports Nutrition, 14: 13.

Abood DA, Black DR, Birnbaum RD, 2004. Nutrition Education Intervention For College Female Athletes. Journal of Nutrition Education and Behavior, 36: 1357.

Akman M, Tüzün S, Ünalan PC, 2012. Adolesanlarda Sağlıklı Beslenme ve Fiziksel Aktivite Durumu. Nobel Medicus, 8(1): 24-29.

Aksoydan E, Çakır N, 2011. Adölesanların Beslenme Alışkanlıkları, Fiziksel Aktivite Düzeyleri Ve Vücut Kitle İndekslerinin Değerlendirilmesi. Gülhane Tıp Dergisi, 53: 264-270.

Akyol A, Bilgiç P, Ersoy G, 2008. Fiziksel Aktivite, Beslenme ve Sağlıklı Yaşam. Sağlık Bakanlığı Yayınları, 1. Baskı, Ankara.

Aracı H, 2006. Öğretmenler ve Öğrenciler için Okullarda Beden Eğitimi. Nobel Akademik Yayıncılık, 6. Baskı, Ankara.

Baş M, Altan T, Dinçer D, Aran E, Kaya HG, Yüksek O, 2005. Determination of Dietary Habits As a Risk Factor of Cardiovascular Heart Disease in Turkish Adolescents. European Journal of Nutrition, 44: 174-182.

Başoğlu S, 2004. Sporcu Beslenmesi. Atasü T, Yücesir İ. Doping ve Futbolda Performans Artırma Yöntemleri.Form Reklam Hizmetleri,1. Baskı, İstanbul.

Braun H, Koehler K, Geyer H, Kleiner J, Mester J, Schanzer W, 2009. Dietary Supplement Use Among Elite Young German Athletes. International Journal of Sport Nutrition and Exercise Metabolism, 19(1): 97. 109.

Bulduk EÖ, Bulduk S, Özkula G, 2018. Assessment of Eating Attitudes and Body Satisfaction among High School Adolescents in Turkey. Progress in Nutrition, 20(2): 205-211.

DeJong CS, Lenthe FJ, Horst K, Oenema A, 2009. Environmental and Cognitive Correlates of Adolescent Breakfast Consumption. Preventive Medicine; 48: 372377. 
Douglas PD, Douglas JG, 1984. Nutrition Knowledge and Foodpractices of High School Athletes.Journal of the American Dietetic Association,84:1198-202.

Ersoy G, Hasbay A, 2008. Sporcu Beslenmesi. Klasmat Matbaacılık Sağlık Bakanlığı Yayın No: 726. 1. Baskı, Ankara.

Goston JL, Correia MI, 2010. Intake of Nutritional Supplements Among People

Exercising in Gyms and Influencing Factors. Nutrition, 26(6): 604-11.

Güleç M, Yabancı N, Göçgeldi E, Bakır B, 2008. Ankara'da İki Kız Öğrenci Yurdunda Kalan Öğrencilerin Beslenme Alışkanlıkları. Gülhane Tıp Dergisi, 50: 102-9.

Helvacı G, Açkurt F, 2018. Özel Spor Merkezlerinde Aktif Olarak Spor Yapan Bireylerin Beslenme Destek Ürünlerini Kullanma Eğilimleri. Türkiye Klinikleri Spor Bilimleri Dergisi, 10(1): 19-28.

Keshani P, Salehi M, Kaveh MH, Faghih S, 2018. Self-Efficacy and Cues to Action: Two Main Predictors of Modified Version of Diet Quality Index in Iranian Adolescents. Progress in Nutrition, 20(2): 197-204.

Korkmaz NH, 2010. Uludağ Üniversitesi Öğrencilerinin Spor Yapma ve Beslenme Alışkanlıklarının İncelenmesi. Uludağ Üniversitesi Eğitim Fakültesi Dergisi, 23(2): 399-413.

Manore MM, Barr SI, Butterfield GE, 2000. Nutrition and Athletic Performance. Medicine \& Science in Sports \& Exercise, 32(12): 2130-2145.

McDowall JA, 2007. Supplement Use by Young Athletes. Journal of Sports Science and Medicine, 6(3): 337-342.

Mor A, Atan T, Agaoglu SA, Ayyildiz M, 2018. Effect of Arginine Supplementation on Footballers' Anaerobic Performance and Recovery. Progress in Nutrition, 20(1): 104-112.

Mor A, Kayacan Y, Ipekoglu G, Arslanoglu E, 2018. Effect of CarbohydrateElectrolyte Consumption on Insulin, Cortisol Hormones and Blood Glucose After High-Intensity Exercise Archives of Physiology and Biochemistry,1-7.

Poole C, Wilborn C, Taylor L, Kerksick C, 2010. The Role of Post-Exercise Nutrient Administration on Muscle Protein Synthesis and Glycogen Synthesis. Journal of Sports Science and Medicine, 9(3): 354-363.

Sevindi T, Yılmaz G, İbiş S, Yılmaz B, 2007. Gazi Üniversitesi Beden Eğitimi Ve Spor Yüksekokulu Öğrencilerinin Beslenme Ve Kahvaltı Alışkanlıklarının Değerlendirilmesi. Türkiye Sosyal Araştırmalar Dergisi, 11(3): 77-90. 
Sobal J, Marquart LF, 1994. Vitamine/Mineral Supplement Use Among High School Athletes. Adolescence, 29(116): 835-843.

Tanrıverdi D, Savaş E, Gönüllüoğlu N, Kurdal E, Balık G, 2011. Lise Öğrencilerinin Yeme Tutumları, Yeme Davranışları ve Benlik Saygılarının İncelenmesi. Gaziantep Tıp Dergisi, 17(1): 33-39.

Türk M, Taner Gürsoy Ş, Ergin I, 2007. Kentsel Bölgede Lise Birinci Sınıf Öğrencilerinin Beslenme Alışkanlıkları. Genel Tıp Dergisi, 17(2): 81-87.

Uzdil Z, Özenoğlu A, Ünal G, 2017. Lise Öğrencilerinde Yeme Tutumlarının Beslenme Alışkanlıkları, Antropometrik Ve Demografik Özellikleri İle İlişkisi. Journal of Duzce University Health Sciences Institute, 7(1): 11-18.

Ünsal GN, Özdemir G, Ersoy G, 2010. The Assessment of the Consumer Awareness in Nutritional Support Products Usage. Fırat Üniversitesi Sağlık Bilimleri Tıp Dergisi, 24(2): 81-88.

Whitehouse G, Lawlis T, 2017. Protein Supplements and Adolescent Athletes: A Pilot Study Investigating the Risk Knowledge, Motivations and Prevalence of Use. Nutrition \& Dietetics, 74(5): 509-515.

Ziegenfuss TN, Landis J, Willoughby D, Greenwood M, 2015. Nutritional Supplements to Enhance Recovery. Greenwood M, Cooke MB, Ziegenfuss T, Kalman DS, Antonio J. Nutritional Supplements in Sports and Exercise. Springer International Publishing, 2. Baskı, İsviçre. 